\title{
METAFICÇÃO COMO TRAÇO DA PÓS- MODERNIDADE EM A RAINHA DOS CÁRCERES DA GRÉCIA, DE OSMAN LINS
}

\author{
Jivago Araújo Holanda Ribeiro Gonçalves
}

\begin{abstract}
RESUMO: Este trabalho parte de uma discussão acerca de aspectos da poética do pós-modernismo presentes no romance brasileiro $A$ Rainha dos Cárceres da Grécia (1976), de Osman Lins. Busco evidenciar o caráter eminentemente metaficcional da narrativa de Osman Lins, com o objetivo de desvelar as tessituras múltiplas da construção do texto, assim como as implicações dessa construção para uma reflexão sobre a condição da literatura, enquanto arte, na pós-modernidade. Lanço mão das formulações de Hutcheon (1991) sobre a poética do pós-modernismo, de Waugh (1984) para uma aproximação da noção de metaficção, e das propostas de Bauman (1998) para uma reflexão sobre o status da arte e do artista na pósmodernidade.
\end{abstract}

Palavras-chave: Metaficção. Pós-modernismo. Pós-modernidade. Osman Lins.

\section{INTRODUÇÃO}

"A literatura é a possibilidade de exceder ficcionalmente aquilo que já foi pensado ou escrito", disse Jonathan Culler (1999, p.46) certa vez ${ }^{1}$ ao buscar uma definição para o conceito de literatura. É possível pensar que $A$ Rainha dos Cárceres da Grécia (1976), do pernambucano Osman Lins, se encaixe nessa tentativa de definição e que ela denote um traço existencial da narrativa pós-moderna: seu teor metaficcional.

A narrativa que demonstra consciência de si, ou seja, que é marcada pelo retorno de seu discurso em direção a si mesma, pode ser definida como metaficcional. Faria (2012) ressalta o caráter pujante dessa escrita:

Por um lado tais ocorrências colocam em evidência o caráter de artefato da obra literária, fazendo com que a ilusão de

\footnotetext{
${ }^{1}$ Não inferimos da citação do autor que este advoga pelo caráter metaficcional da literatura, mas sim que a literatura é eminentemente um diálogo aberto consigo mesma, na busca de sua renovação. Portanto a possibilidade de se pensar, a partir daí, o tema da metaficção aqui proposto.
} 
realidade da obra ficcional seja interrompida; por outro, as narrativas assim construídas são invadidas pela crítica e/ou pela teoria literária, tornando-se, assim, uma forma híbrida, em que a ficção, a crítica e a teoria partilham o mesmo espaço literário. (2012, p. 237-238)

É esta miríade de possibilidades que nos relata um dos narradores de $A$ rainha... Numa busca constante pelo melhor método de análise, seu ponto de vista fornece ao leitor o fio condutor de uma narrativa que são muitas. Através deste recurso somos levados a revisitar nossas percepções enquanto leitores face às narrativas, bem como a revisitar conceitos fundamentais à criação literária e à suas teorias, a saber: o narrador, o gênero literário, o significado, e o próprio leitor. O que se coloca em cheque são as limitações dessas categorias enquanto elementos que interagem entre si. A Rainha dos Cárceres da Grécia é um grande questionamento sobre essas possibilidades.

Visto que a construção do romance se dá a partir de uma sobreposição de vozes e de gêneros - resumo, ensaio, diário, romance-reportagem - a sua identidade pode ser pensada como metaficcional. Não só há uma mistura de gêneros, como essa mistura serve ao propósito de desestabilizar algumas noções essencialistas de narrativas. Como homem de seu tempo e conhecedor da arte do romance, Osman Lins lança um olhar crítico em direção às configurações sociais resultantes do contexto político no qual está inserido:

A rainha dos cárceres da Grécia apresenta esse procedimento, mas, além de não ser recurso predominante, tem objetivos diferentes dos romances-reportagem. As notícias retiradas dos jornais são colocadas em função de um todo: a temática da dominação dos oprimidos e injustiçados pelos poderosos. (HASMANN, 2008, p. 151)

Mas explorar a fluidez desta narrativa inserida num contexto de produção pós-moderno é também voltar nossos esforços para inferir que imagens, representações e/ou significações são alcançadas enquanto efeitos deste teor metaficcional. Portanto, é necessária a apreciação da proposta metaficcional em conjunto com as postulações conceituais pós-modernas que lidam com as instâncias mencionadas acima. Para este trabalho, lanço mão das formulações de Bauman (1998) que analisa essa fluidez enquanto um mal-estar consequente do abandono de uma "ordem" pressuposta anteriormente pela civilização moderna, daí que a pós-modernidade se encontra em um estado de insegurança, onde as certezas foram abandonadas. $O$ abandono de tais certezas é precisamente o suporte que nos auxiliará na compreensão do teor metaficcional do romance de Osman Lins.

\section{A(S) NARRATIVA(S) DO ROMANCE}

Se se decide estudar um romance, qual a melhor forma de fazê-lo? A pergunta é pertinente a todos aqueles que se dedicam às ciências literárias e é 
também reveladora do leitmotiv que norteia as ações de um dos personagens, talvez o principal, de $A$ rainha dos Cárceres da Grécia. Entretanto, aqui se faz necessário um adendo, pois o romance que toma forma a partir da imaginação de Osman Lins é homônimo doutro romance não publicado e inserido no fluxo diegético da narrativa, cuja autora se chama Julia Marquezim Enone.

A personagem que postulamos acima como principal, em teor de possibilidade, nos é apresentada como um amigo de J.M. Enone, certo professor de biologia que tenta no início do romance decidir-se entre "a intenção de ocupar as horas vagas, dar-lhes sentido talvez, escrevendo o que Julia - Julia Marquezim Enone -, sempre discreta em relação a si mesma, me contou da sua vida, o que testemunhei e o que depois pude saber." (LINS, 2005, p.7) e "[...] dedicar um estudo ao livro, o seu, que sempre leio?" (LINS, 2005, p.8). Uma vez dada por certa a necessidade de rememorar sua convivência com a escritora, que já reside no passado, o analista resolve que tomará outro rumo:

Quero um ensaio onde, abdicando da imunidade do tempo, e, em consequência, da imunidade à surpresa e à hesitação, eu estabeleça com o leitor - ou cumplice - um convívio mais leal. Que outra opção, neste caso, impõe-se mais naturalmente que o diário? Assim, dia a dia seguireis o progresso e as curvas das interrogações que me ocorram.(LINS, 2005, p.14)

Portanto, o leitor tem em mãos um romance que é a história, ou melhor, um relato em forma de diário, da análise de outro romance homônimo. Porém, o excerto destacado anteriormente poderá revelar mais do que aparenta. A personagem que se dedicará ao feitio da análise literária pretende transformar a rotina deste esforço em um diário, e o faz para que "o progresso e as curvas" que se apresentarão no decorrer de sua atividade interpretativa ressalte uma presença basilar neste processo: a do próprio leitor, que é ao mesmo tempo o leitor de seu diário e o leitor do romance de Osman Lins, podendo os dois ser tomados como um mesmo, como demarcado no trecho adiante:

No caso de Julia Marquezim Enone, o texto a ser apreciado, é verdade, não chegou a ser impresso. [...] Circunscrito ainda aos originais, não franqueado, portanto, a quem deseje e possa tê-lo consigo, já pertence a todos? Inclino-me a supor que sim. A obra, mesmo embrionária, concerne ao ente coletivo - nós de cuja substância ela se forma. (LINS, 2005, p. 8-9).

É assinalável a presença do pronome pessoal nós onde o narrador indica a consciência de um discurso que leva em consideração a participação do leitor como agente construtor do sentido que pretende veicular a partir da obra. O "nós" enquanto "ente coletivo" pode ser pensado como marca de uma significação que não é estagnada e nem centrada em qualquer categorização literária a priori, mas que depende do engajamento coletivo e do processo de 
reposicionamento do narrador, do leitor e da própria narrativa, à medida que esta avança. Consequentemente, o que se sobressai é que há uma consciência da presença do leitor e, já se pode afirmar, de sua relevância quanto à construção de significado do texto, pois o leitor é inferido como importante peça para o funcionamento das análises literárias da personagem.

De imediato o professor de biologia no faz cientes da construção narrativa que se desenvolve no romance que analisará e nos diz:

Contrariando deliberadamente o mais difundido e respeitado dogma da ficção moderna o que condena o enredo, estrutura $A$ rainha dos cárceres da Grécia mediante uma cadeia ininterrupta de fatos, centrados em Maria de França, heroína parda e pobre, perdida nas escadas, nos corredores e nas salas da burocracia previdenciária, onde luta por determinado benefício. (LINS, 2005, p.15)

Temos aqui a caracterização de outra personagem principal, desta vez trata-se de uma personagem do romance de J.M. Enone. Maria de França é caracterizada como "heroína" e ao mesmo tempo "pobre" e "perdida", e mais à frente nos é reportado que também é louca. Sua missão: a conquista do benefício de sua aposentadoria. Desta forma, o professor de biologia tem como missão o relato da experiência de Maria de França concernente à conquista de seu benefício. Ciente destes posicionamentos narrativos, Hassman (2008) questiona-se sobre uma intenção velada de Osman Lins quanto ao narrador: teria este apenas a função de estabelecer o diálogo, ou o romance de Osman Lins coloca em cena uma tese "inovadora" sobre o narrador? Para o autor anteriormente citado, Osman Lins está preocupado com a recuperação do efeito da catarse oriundo da experiência do leitor frente à obra de arte literária. Daí que a dedicação do professor de biologia à exegese do romance se inscreve ao nível da descoberta de si mesmo. "À medida que penetra no labirinto que é o romance não publicado, à medida que começa a desvendá-lo, o professor, paradoxalmente, se envolve com outro: sua própria personalidade, seu próprio "eu" que está perdido." (HASMANN, 2008, p.154).

\section{METAFICÇÃO E A ARTE NA PÓS-MODERNIDADE}

Na perspectiva de uma narrativa que se constrói múltipla, e que prioriza o jogo de significações, podemos retomar um questionamento pertinente a esse tipo de fazer literário: ele surge despretensiosamente ou pode ser visto como um sintoma de uma época? Partindo das postulações de Waugh (1984) é assinalável o caráter vinculador da metaficção enquanto estratégia que busca pensar as relações entre o real e o fictício. É o que a autora propõe a partir da seguinte definição:

Metafiction is a term given to fictional writing which selfcounsciously and systematically draws attention to its status as an artefact in order to pose questions about the relationship 
between fiction and reality. In providing a critique of their own methods of construction, such writings not only examine the fundamental structures of narrative fiction, they also explore the possible fictionality of the world outside. (WAUGH, 1984, p. 2)

Concordo com a autora em relação à proposta de que metaficção é a literatura em seu estado auto-consciente. Isto implica pensar que a escrita literária e seus processos constituintes contribuem para sua própria apreensão enquanto artefato, e que usam essa autoconsciência acerca de sua própria natureza no intuito de propor questionamentos sobre a dinâmica que vincula o real e o ficcional. Em maior medida, é precisamente essa autoconsciência do narrador, como um veiculador de experiências através de um objeto artístico dotado de particularidades, que permite o autoquestionamento acerca desse processo e suas implicações.

Ao se dedicar à discussão acerca da literatura brasileira contemporânea Schollhammer (2009) insere-se nesse cenário de postulações acerca do metaficcional e assinala que a partir dos anos 1980 uma tendência pósmodernista domina o cenário de produção literária nacional e que:

\footnotetext{
"essa vertente pós-moderna era a combinação híbrida entre alta e baixa literatura, propiciada pelo novo diálogo entre a literatura, a cultura popular e a cultura de massa, ou a mescla entre os gêneros de ficção e as formas da não ficção como a biografia, a historia e o ensaio." (p.31)
}

O autor ressalta, ainda, que esse tipo de escrita "trata-se de literatura sobre literatura, ficção que discute sua própria construção e reflete sobre como tais mecanismos afeta a percepção do mundo que se costuma reconhecer como real." (SCHOLLHAMMER, 2009, p. 30). É a partir dessa perspectiva que Osman Lins antecipa uma tendência metaficcional que se fortaleceria na década de 80 a partir da democratização. Assim podemos constatar essa dobra da literatura sobre si mesma durante o percurso interpretativo do professor de biologia:

\footnotetext{
Neste ponto, penso em algo inviável: uma obra que se apresentasse desdobrada, construída em camadas e que fingisse ser a sua própria análise. Por exemplo: como se não houvesse Julia Marquezim Enone e $A$ rainha dos cárceres da Grécia, como se o presente escrito é que fosse o romance desse nome e eu próprio tivesse existência fictícia. Tal obra, se possível, qual o seu destino? Condenariam ou absolveriam o criador que ousara aventurar-se, nu, em domínio alheio? (LINS, 2005, p. 55).
}

À frente do leitor, se estabelece por meio desse trecho o ponto de maior expressão do teor metaficcional da narrativa. O analista do romance de J.M. Enone desvela, em tom de confissão, todas as camadas narrativas da obra, e o 
faz através da sugestão. Ele não afirma possuir alguma certeza, tampouco estabelece uma verdade sobre o processo metaficcional; mas ao indagar-se sobre essa possibilidade, joga luz sobre sua natureza. As indagações e os pontos de interrogação assinalam a dúvida quanto à recepção provável de obras que empreendem semelhante esforço metaficcional e os efeitos dessa criação, lançando, novamente, dúvidas sobre sua aceitação e incerteza perante o futuro desse gênero.

Todavia, é preciso refletir sobre quais experiências de sujeitos e subjetividades acabaram sendo postas em evidência, a partir da expressão literária, e através da marca da pós-modernidade. Desta forma, a própria definição de pós-moderno "depende, principalmente, de uma nova posição do sujeito marcada pela expressão literária de uma individualidade desprovida de conteúdo psicológico, sem profundidade e sem projeto." (SCHOLLHAMMER, 2009, p. 30).

A heroína do romance ao qual se dedica o professor de biologia desponta como alguém que carece dos meios necessários para dar sentido a sua vivência em meio ao caos urbano e às complicações legais que se envolve pela busca de seu benefício de aposentadoria. Com a sucessão dos fatos na vida de Maria de França, o narrador nos expõe a própria condição do sujeito ex-cêntrico proposto por Hutcheon (1991) na qual a personagem se situa: "Ela, na fábrica de tecidos, chora de alegria quando assinala pela primeira - e última - vez o recibo: demitem-na a seguir, para não completar o chamado "período de carência". (LINS, 2005, p. 22). Estes fatos se sucedem em sua vida sem que nos seja apresentado sua percepção daquilo que lhe afeta. A passividade de Maria de França é testemunho de sua impotência e uma amostra da fraqueza do indivíduo que não carrega em si as forças que o governam, como é possível inferir a partir do seguinte trecho:

Afinal examina-a e garante ser possível, no seu caso, um ano de licença. Mas não tenha como certo, não cabe a ele a decisão final. Cabe a quem? À junta médica superior. Longo, depreende-se, o tempo decorrido entre essa informação e o veredicto, contrário, da junta médica. Maria de França, enquanto espera, tenta obter trabalho em casas de família e, entre uma tentativa e outra, ajuda a mãe na barrela. (LINS, 2005, p. 27).

A representação, livre de travessão, da voz do médico (a personagem que examina Maria de França) assinala um efeito de estilo: mesmo o menor recorte da fala é relatado de maneira a parecer algo banal e corriqueiro, quando sabemos tratar-se do destino de Maria de França e sua aposentadoria. A heroína está presa num turbilhão burocrático do qual precisa absorver algum sentido sem se perder nessa malha multidirecional que a cerca.

Este sujeito que não está no centro, ou que é propositalmente colocado fora dele, é que possibilita a crítica relativa aos ideais do humanismo liberal 
que marcam toda a tradição literária anterior ao pós-modernismo, como demarcado por Linda Hutcheon:

Assim como grande parte da teoria literária contemporânea, o romance pós-modernista questiona toda aquela série de conceitos inter-relacionados que acabaram se associando ao que chamamos, por conveniência, de humanismo liberal: autonomia, transcendência, certeza, autoridade, unidade, totalização, sistema, universalização, centro, continuidade, teleologia, fechamento, hierarquia, homogeneidade, exclusividade, origem. No entanto, conforme tentei mostra, questionar esses conceitos não significa negá-los - mas apenas indagar de sua relação com a experiência [...]. (HUTCHEON, 1991, p. 84)

O debate sobre o centro - e as premissas do humanismo liberal que pesam sobre essa noção - é essencial para o entendimento da empresa conceitual pós-moderna. A descentralização do sujeito começa a ganhar força quando o contexto em que está inserido passa a influir sobre construção de sua identidade. Mas que reflexo dessa centralização poderá ser observado na dinâmica da construção narrativa? Somos levados a concluir que a própria narrativa apresentará rupturas de continuidade e construção; o fechamento narrativo, como propõe Hutcheon, não serve mais ao propósito da heterogeneidade constitutiva do sujeito. Assim, a autora enfatiza que:

O movimento da diferença e da heterogeneidade para a descontinuidade é um elo que pelo menos a retorica da ruptura não demorou à estabelecer à luz das contradições e dos desafios do pós-modernismo. A continuidade narrativa é ameaçada, usa-se e abusa-se dela, inserida e subvertida. As estruturas de fechamento narrativo do século XIX (morte, casamento; conclusões ordenadas) são minadas por esses epílogos pós-modernos, que colocam em evidencia a maneira como, enquanto autores e leitores, nós produzimos o fechamento[...]. (HUTCHEON, 1991, p. 86)

A perspectiva narrativa em $A$ rainha dos cárceres da Grécia é perpassada pelo tom da fragmentação constante; isso se deve à voz do analista do romance de J.M. Enone que, repetidamente, falha no autoreconhecimento de sua autoridade enquanto leitor do romance que interpreta e, diversas vezes, cede espaço para que as intenções da autora desempenhem a função de liame que agregam sentido aos trechos analisados. Podemos identificar aqui uma sobreposição de vozes. Consequentemente, esse jogo de vozes é transfigurado em uma grande questão de fundo: a reflexão acerca da verdade da obra de arte; e o leitor é trazido para o centro desse debate, uma vez que as verdades enunciadas não são fechadas e definitivas, mas sim trazidas à tona a partir de indagações.

Em termos de uma condição pós-moderna como preconizada por Lyotard em sua obra O pós-moderno (1979), pode-se pensar a construção narrativa que surge dessa condição como o campo fértil de "decomposição dos grandes Relatos" 
(LYOTARD, 1979, p. 28). Ou seja, a negação de estruturas fixas e de narrativas universais para lidar com a "textura de relações mais complexa e mais móvel do que nunca" (LYOTARD, 1979, p. 28). Se o diagnóstico da composição de tal condição pós-moderna, a partir das formulações de Lyotard, aponta primordialmente para a necessidade de atribuição de importância ao papel da linguagem nesse processo de decomposição dos grandes relatos, tendo em vista que o sujeito é "colocado nas posições pelas quais passam mensagens de natureza diversa" (LYOTARD, 1979, p. 28), narrativa Osmaniana aparenta cooperar com a criação de sujeitos inseridos em nesses jogos de comunicação, portanto dando um testemunho de uma condição pós-moderna via estruturação metaficcional.

Ao citar o psicanalista Sigmund Freud e seu ensaio O mal-estar na civilização, Bauman (1998) situa a pós-modernidade como um constante estado de medo e insegurança advindos do arrefecimento da pretensa "ordem" que vigorava durante a modernidade:

"Ordem" significa um meio regular e estável para os nossos atos; um mundo em que as probabilidades dos acontecimentos não estejam distribuídas ao acaso, mas arrumadas numa hierarquia estrita - de modo que certos acontecimentos sejam altamente prováveis, outros menos prováveis, alguns virtualmente impossíveis. (BAUMAN, 1998, p. 15).

Essa ordem, pensada através da perspectiva sociológica, não existe na rotina de Maria de França. A personagem é continuamente alijada de sua própria constituição enquanto sujeito, tanto juridicamente - se nos referirmos aos trâmites intermináveis de seu processo em busca de sua aposentadoria, que a deslocam de uma repartição pública à próxima sem que se crie uma expectativa otimista para o desfecho desta odisseia judicial - quanto existencialmente falando, vez que sua inocência juvenil lhe é tomada através de uma relação sexual com Belo Papagaio e de maneira instantânea é apresentada ao leitor como um fato passageiro, devido à incapacidade da personagem de apreender a amplitude do ato, causando o efeito de quebra quanto a qualquer pretensão romântico-idealizada do sexo, como notado a partir do seguinte trecho:

\footnotetext{
"[...]não obstante os quarenta e tantos anos, deflora Maria de França e, antes que amanheça o dia, azula no tempo. O episodio não traz as consequências que tememos. Resta na vitima, como vestígio da passagem de Belo Papagaio, o costume de esconder os polegares." (LINS, 2005, p. 21).
}

A ordem também não se manifesta nas análises, que se pretendem sistemáticas, do romance de J.M. Enone. Portanto, é seguro afirmar que o romance pós-moderno nega ao leitor essa ideia de limpeza e ordem, e o faz não só pela sua forma, mas por via da construção de seus personagens. É por meio desta negação da fixidez narrativa que $A$ Rainha dos Cárceres da Grécia 
pode espelhar uma "essência" da arte pós-moderna que é a sua constante reformulação das perguntas que se voltam para si mesmas em busca de elucidar noções como representação do real, limites da própria narrativa, e participação do leitor/receptor no processo de criação dos sentidos, como ressalta Botoso:

Um dos aspectos mais polêmicos da arte pós-moderna é o fato de que ela problematiza questões (o sujeito, a recepção, a autoria, a originalidade) e mantém as suas contradições para que se possa compreendê-las enquanto processo. Tal arte retoma a prática da ruptura em todos os seus setores proposta pelo modernismo, mas estabelece uma diferença em relação a esse procedimento. Não nega o passado, mas vai um pouco mais além, contestando e propondo uma revisão e uma revalorização do modernismo. (BOTOSO, 2004, p. 98)

Tal postura inquieta que encontramos em $A$ Rainha dos cárceres da Grécia é reforçada pela análise de Bauman (1998) sobre a polifonia das significações como consequência do fazer artístico pós-moderno:

\begin{abstract}
A obra do artista pós-moderno é um esforço heroico de dar voz ao inefável e uma conformação tangível ao invisível, mas é também (obliquamente, através da recusa a reafirmar os cânones socialmente legitimado dos significados e suas expressões) uma demonstração de que é possível mais do que uma voz ou forma e, desse modo, um constante convite a se unir no incessante processo de interpretação, que também é o processo de criação do significado. [...] O significado da arte moderna, pode-se dizer, é estimular o processo de elaboração do significado e defendê-lo contra o perigo de, algum dia, se desgastar até uma parada; alertar para a inerente polifonia do significado e para a complexidade de toda interpretação[...]. (BAUMAN, 1998, p. 134-136)
\end{abstract}

Nesse sentindo, o esforço para interpretar o romance de Júlia Marquezim e a polifonia que daí surge em consequência da busca pelo sentido são o retrato fiel do posicionamento pós-moderno do artista, do leitor e da obra. 0 romance de Osman Lins resulta num intrincado jogo de deslocamento desses posicionamentos, com vistas à movimentação e a reelaboração dos significados do texto, que resistem ao esgotamento perante a autoridade, seja do autor, da personagem, ou mesmo do próprio leitor.

\title{
CONSIDERAÇÕES FINAIS
}

Considero ser possível afirmar que a aproximação em direção $A$ Rainha dos cárceres da Grécia permite-nos inferir a construção da narrativa metaficcional como traço representativo da produção literária da pósmodernidade. Se há uma clara consciência do discurso artístico dentro da própria narrativa, esta serve ao propósito de desestabilizar a fixidez de algumas noções concernentes a este fazer artístico, a saber: construção de 
sentido, representação do real, autoria perante a obra, e as fronteiras entre os gêneros literários.

Particularmente, no romance de Osman Lins sobressaem-se dois aspectos da metaficção, o primeiro sendo a reflexão acerca das técnicas e escolhas para a construção do romance que refletem o ofício do fazer literário, como é possível notarmos a partir da elucubração do professor de biologia enquanto analista:

Imaginar desejos, contratempos, embates, desistências, o triunfo ou a morte prende-se à invenção em estado bruto. Nasce o romancista com o ato de dispor esses eventos e de elaborar uma linguagem que não sabemos se os reflete ou se apenas serve-se deles para existir. (LINS, 2005, p.16).

O segundo aspecto podendo ser apontado como a consciência de um fazer literário que dialoga com uma tradição:

\footnotetext{
Patente a minha desvantagem em um confronto com os fictícios autores de diário imaginados por Goethe (Werther), por Machado de Assis (Memorial de Aires), por Gide (Sinfonia pastoral). Ocupavam-se todos de mulheres - de Carlota, de Fidélia, de Gertrudes -, enquanto meu herói é só um livro. Ao menos favorece-me a circunstância não pouco valiosa de que o livro e eu somos reais. (LINS, 2005, p. 14).
}

Ao assinalar seu posicionamento em relação ao cânone relativo ao gênero "diário", revela a consciência de sua produção inserida numa tradição e, por conseguinte, dialogando com esta tradição. Em última análise, a narrativa metaficcional de Osman Lins se estabelece como um ponto de confluência em que se espelham os questionamentos genuinamente marcados pela pósmodernidade, onde não só a condição existencial da narrativa é posta em cheque, como também os relatos de experiências de sujeitos e subjetividades que a partir daí ganham nova roupagem, e que, representam uma reação ao que Hutcheon (1991) aponta como as premissas do humanismo liberal. Portanto, em $A$ Rainha dos cárceres da grécia há uma revitalização da própria narrativa enquanto arte engajada com as premissas de seu tempo.

\title{
METAFICTION AS A TRACE OF POST-MODERNITY IN OSMAN LINS' A RAINHA DOS CÁRCERES DA GRÉCIA
}

\begin{abstract}
This study is developed from a discussion over aspects of the poetics of postmodernism which are present in the Brazilian novel A Rainha dos Cárceres da Grécia (1976), by Osman Lins. I seek to highlight the metafictional character of Osman Lins's narrative and unveil the multiple textures in the making of the
\end{abstract}


text, as well as the implications of this writing process to a reflection about the condition of literature, as art, in post-modernity. I make use of the formulations presented by Hutcheon (1991) about the poetics of post-modernism, and the proposals of Bauman (1998) towards a reflection that deals with the status of art and artists in post-modernity.

Keywords: Metafiction. Postmodernism. Postmodernity. Osman Lins.

\section{REFERÊNCIAS}

BAUMAN, Z. O mal-estar da pós-modernidade. Rio de Janeiro: Zahar, 1998.

BOTOSO, A. "Pós-modernidade e literatura na América Latina". Travessias, Unioeste, v.11, p. 96-113, 2004.

CULLER, J. Teoria Literária - uma introdução. São Paulo: Becca produções culturais Ltda, 1999.

FARIA, Z. de. "A metaficção revisitada: uma introdução". Signótica, Goiânia, CEGRAF-UFG, v.24, n.1, p. 237-251, Jan/Jun., 2012.

GOMES, L. da S. "Osman Lins: últimos movimentos de uma poética”. Revista Intercambio dos Congressos Internacionais de Humanidades, Brasília, v.1, p. 1-11 2012.

HASMANN, R. "O posicionamento do narrador em A Rainha dos Cárceres da Grécia, de Osman Lins”. Literatura y Linguistica, Santiago, n. 19, 145-164, 2008.

HUTCHEON, L. Poética do pós-modernismo: história, teoria e ficção. Rio de Janeiro: Imago, 1991.

LINS, O. A Rainha dos Cárceres da Grécia. São Paulo: Companhia das letras, 2005.

LYOTARD, J. O pós-moderno. 3. Ed. Rio de Janeiro: José Olympio, 1990.

SCHOLLHAMMER, K. E. Ficção brasileira contemporânea. Rio de Janeiro: Civilizaçao Brasileira, 2009.

WAUGH, P. Metafiction: the theory and practice of self-counscious fiction. New York: Methuen, 1984. 